\title{
High Concentrations of Very Long Chain Leaf Wax Alkanes of Thrips Susceptible Pepper Accessions (Capsicum spp)
}

\author{
Mirka Macel $^{1,2}$ - Isabella G. S. Visschers ${ }^{1}$ • Janny L. Peters ${ }^{3} \cdot$ Nicole M. van Dam $^{1,4,5} \cdot$ Rob $^{\text {M. de Graaf }}{ }^{6}$ (D)
}

Received: 16 July 2020 / Revised: 25 September 2020 / Accepted: 9 October 2020 / Published online: 22 October 2020

(C) The Author(s) 2020

\begin{abstract}
The cuticular wax layer can be important for plant resistance to insects. Thrips (Frankliniella occidentalis) damage was assessed on 11 pepper accessions of Capsicum annuum and C. chinense in leaf disc and whole plant assays. Thrips damage differed among the accessions. We analyzed the composition of leaf cuticular waxes of these accessions by GC-MS. The leaf wax composition was different between the two Capsicum species. In C. annuum, 1-octacosanol ( $\mathrm{C}_{28}$ alcohol) was the most abundant component, whereas in $C$. chinense 1-triacotanol $\left(\mathrm{C}_{30}\right.$ alcohol $)$ was the prominent. Thrips susceptible accessions had significantly higher concentrations of $\mathrm{C}_{25}-\mathrm{C}_{29} n$-alkanes and iso-alkanes compared to relatively resistant pepper accessions. The triterpenoids $\alpha$ - and $\beta$-amyrin tended to be more abundant in resistant accessions. Our study suggests a role for very long chain wax alkanes in thrips susceptibility of pepper.
\end{abstract}

Keywords Capsicum · Wax metabolites · Alkanes · Triterpenoid · Thrips · Resistance $\cdot$ Plant defense

\section{Introduction}

The cuticular wax layer of the leaf is a first barrier for an herbivorous insect to tackle after landing on the leaf surface. Plant cuticular waxes can consist of very long chain $(>20 \mathrm{C})$

Electronic supplementary material The online version of this article (https://doi.org/10.1007/s10886-020-01226-x) contains supplementary material, which is available to authorized users.

Rob M. de Graaf

rdegraaf@science.ru.nl

1 Molecular Interaction Ecology, Institute of Water and Wetland Research (IWWR), Radboud University, P.O. Box 9010, 6500 GL Nijmegen, The Netherlands

2 Institute of Biology, Plant Ecology and Phytochemistry, Leiden University, P.O. Box 9505, 2300 RA Leiden, The Netherlands

3 Plant Systems Physiology, Institute of Water and Wetland Research (IWWR), Radboud University, P. O. Box 9010, 6500 GL Nijmegen, The Netherlands

4 German Centre for Integrative Biodiversity Research (iDiv) Halle-Jena-Leipzig, Deutscher Platz 5e, 04103 Leipzig, Germany

5 Institute of Biodiversity, Friedrich Schiller University Jena, Dornburger-Str. 159, 07743 Jena, Germany

6 Microbiology, Institute of Water and Wetland Research (IWWR), Radboud University, P.O. Box 9010, 6500

GL Nijmegen, The Netherlands alkanes, ketones, alcohols, fatty acids and triterpenoids (Eigenbrode and Espelie 1995). The primary function of this wax layer is to protect the plant against desiccation, solar radiation and pathogens (Jenks et al. 1995; Mariani and Wolters-Arts 2000). The wax layer can be a physical barrier for insects to attach to or penetrate the leaf surface (Eigenbrode and Espelie 1995). The triterpenoids and other metabolites in the wax layer can be feeding or oviposition deterrents for herbivorous insects (Eigenbrode and Pillai 1998). For example, amyrins (triterpenoids) reduced feeding by diamandback moth larvae on cabbage (Eigenbrode and Pillai 1998). On the other hand, some wax metabolites can also be used for host plant recognition and as feeding stimulants by various insects such as sawflies and flea beetles (Braccini et al. 2015; Mitra et al. 2017; Müller and Hilker 2001; Udayagiri and Mason 1997). Relatively high amounts of leaf wax have been associated with higher susceptibility against thrips in onions and leak (Damon et al. 2014). This means that the chemical composition of the wax layer can have positive and negative effects on herbivore resistance.

Thrips (Thysanoptera) are a major agricultural pest worldwide. In greenhouses in Europe, western flower thrips (Frankliniella occidentalis) is a generalist pest on many crops. Thrips are sucking piercing insects that cause deformations and stunted growth, and cause damage by spreading viruses (Steenbergen et al. 2018). Recent bans on pesticides and increasing resistance to the insecticides that are still used call for 
identifying natural sources of resistance in crops. Plant metabolites linked to thrips resistance are amongst others alkaloids (Liu et al. 2019), chlorogenic acid (Leiss et al. 2009), tocopherols (Maharijaya et al. 2012) and diterpene glycosides (Macel et al. 2019; Maharijaya et al. 2018). However, in most studies the entire leaf was analyzed and not specifically the wax compounds. Most of the above-mentioned compounds are not present in the epicuticular wax layer, although very small traces of alkaloids have been found in the wax layer of leaves of Senecio jacobaea (Vrieling and Derridj 2003). This means that the contribution of wax layer chemistry, which commonly consist of apolar components, to thrips resistance are relatively unknown.

Peppers (Capsicum spp., Solanaceae) are grown worldwide and damage by several thrips species causes great economic losses (Shipp et al. 1998, Visschers 2020). Commercially grown peppers generally belong to the species Capsicum annuum and C. chinense. Because of their economic interest, there has been quite some research on the wax layers of the pepper fruits in relation to food quality and food preservation (de Rijke et al. 2015). Major components of the fruit wax layer were $\mathrm{C}_{29}$ and $\mathrm{C}_{31} n$-alkanes and $\mathrm{C}_{24}$ fatty acid (Bauer et al. 2005; de Rijke et al. 2015; Parsons et al. 2013). Both plant ontogeny and leaf age play a role in cuticular wax metabolite composition (Busta et al. 2017). In addition, abiotic and biotic factors influence plant waxes (Shepherd and Griffiths 2006). For example, bacterial root endophytes can influence the concentrations of wax metabolites in the leaves and fruits (Silva et al. 2014). How leaf wax metabolites relate to thrips resistance in peppers has not been studied yet.

Here, we analyzed the leaf cuticular wax layer composition of previously identified thrips resistant and susceptible Capsicum annuum and C. chinense accessions, using Gas Chromatograph coupled to Mass Spectrometry (GC-MS). We grew the 11 selected accessions in the greenhouse and analyzed the cuticular wax metabolites of young leaves from flowering plants. We related differences in wax chemical composition to the outcome of thrips ( $F$. occidentalis) leaf disc and whole plant preference and performance assays. An earlier study that analyzed entire leaves of nine Capsicum accessions of four species (C. annuum, $C$. chinense, $C$. frutescens, $C$. baccatum) showed that thrips susceptible accessions had relatively high concentrations of $\mathrm{C}_{25}-\mathrm{C}_{28} n$-alkanes (Maharaijya et al. 2012). Because alkanes are the major constituents of the wax layer, we hypothesized that the concentration of $n$-alkanes in the epicuticular wax would be higher in thrips susceptible Capsicum accessions. Triterpenoids (phytosterols) are known to be involved in constitutive and herbivore induced plant defenses (Eigenbrode and Pillai 1998; Zhang et al. 2018). Therefore, we hypothesized that triterpenoid concentrations in the wax layer would be higher in thrips resistant Capsicum accessions.

\section{Materials and Methods}

\section{Leaf Wax Metabolites GC-MS Analyses}

Plant Material Seeds of all accessions were obtained from the Center for Genetic Resources Netherlands (Table S1) and selected based on prior knowledge on insect resistance. The seeds were multiplied in the greenhouses of the Radboud University Nijmegen. Seeds were germinated on glass beads and seedlings transferred to $1.5 \mathrm{~L}$ pots filled with commercial potting soil 1-2 weeks after germination. The pots were placed on tables in a greenhouse, inside an insect-free net cage (Rovero $0.30 \mathrm{~mm}$ gauze, $7.50 \mathrm{~m} \times 3 \mathrm{~m} \times 2.75 \mathrm{~m}$ ) at $16 \mathrm{~h}$ photoperiod and minimum temperatures set to $20{ }^{\circ} \mathrm{C} / 17{ }^{\circ} \mathrm{C}$ (day/night). Natural light was supplemented with Greenpower lights (400V/1000W, Phillips, Amsterdam, the Netherlands) when below 200Watt m-2. Predatory mites, Amblyseius swirskii (Koppert Biological Systems, Berkel en Rodenrijs, the Netherlands), were released in the greenhouse to control for accidental thrips infection. Plants were transferred to $3 \mathrm{~L}$ pots when they were three months old and provided with nutrients once a week.

\section{Thrips Resistance Assessments}

Leaf Disc No-choice Assay These experiments were previously published as part of Visschers et al. 2019a. The purpose of nochoice assays was to determine thrips resistance of the pepper accessions per se and not thrips preference. In brief, three plants of the selected accessions were grown in the greenhouse. After four months, when all plants were flowering, one standardized leaf of each plant was collected. Leaf discs ( $1.5 \mathrm{~cm}$ diameter) were punched from the leaves. One leaf disc of each accession was put in a small petri dish with five L1/L2 $F$. occidentalis larvae (reared on green beans) and left to feed for $48 \mathrm{hrs}$. Leaf damage was assessed using imaging software (Visschers et al. 2018a, b).

Leaf Disc Choice Assay These experiments were previously published as part of Macel et al. 2019. In brief, the same accessions were used in a leaf disc choice assay. Ten plants of each accessions were grown in the greenhouse and leaf discs were taken from a standardized set of leaves of four months old flowering plants. One disc of each accession was placed in a petridish, which contained in total 11 discs (one of each accession, in randomized order for each petri dish). Twenty-two L1/L2 F. occidentalis larvae were added to the petri dish and left to feed for $48 \mathrm{hrs}$. Leaf damage was assessed in the same manner as the nochoice leaf disc assay.

Whole Plant Assay Seeds of the eleven accessions were sown in potting trays for germination and transferred to $1 \mathrm{~L}$ pots with 
potting soil. One to three plants per accession were grown individually in closed nylon mesh bags $(1 \mathrm{~m}$ length $\mathrm{x} 0.5 \mathrm{~m}$ diameter) in the greenhouse. Temperatures were set to 24/ $24{ }^{\circ} \mathrm{C}$ and light was supplemented when below $400 \mathrm{~W} / \mathrm{m}^{2}$ using 10.000 lux Son-T lamps. When the plants were four weeks old they were infested with 50 adult $F$. occidentalis females. Five weeks after thrips inoculation, the damage on the plants was scored on a scale from one to nine $(1=$ severe damage, $9=$ no damage). The number of larvae and adult thrips on the plants was counted by washing the entire plant with ethanol and filtering out the thrips.

Wax Layer Metabolite Extraction Methods adapted from Haslam and Kunst (2013). Two leaves, the second pair from the top (similar to the leaves used in the thrips leaf disc experiments), were collected from each plant ( $n=2-7$ plants per accession) when they were four months old and flowering. Wax metabolites were extracted by dipping the leaves for 30 seconds in $10 \mathrm{ml}$ chloroform with $10 \mu \mathrm{l}$ internal standard (tetracosane (Sigma-Aldrich) $1 \mathrm{ug} / \mu \mathrm{l} \mathrm{chlo-}$ roform solution) using a glass vial. Chloroform was evaporated under a stream of nitrogen gas (5.0) and the wax residue resuspended in $200 \mu \mathrm{l}$ chloroform and transferred to a glass $1.5 \mathrm{ml}$ vial. After evaporation of the chloroform, $10 \mu \mathrm{l}$ dried pyridine and $10 \mu \mathrm{l}$ BSFTA (N,O-Bis(trimethylsilyl)trifluoroacetamide) (Merck) were added and the vials were sealed with phenolic polytetrafluoroethylene (PFTE) lined caps. Samples were incubated at $80^{\circ} \mathrm{C}$ for 1 hour. Samples were allowed to cool off and evaporate, after which the samples were resuspended in $40 \mu \mathrm{l}$ chloroform and transferred to glass $1.5 \mathrm{ml}$ vials with $200 \mu 1$ inserts.

Leaf Area Directly after dipping in chloroform, the leaves were placed flat on a transparent sheet with a centimeter and photographed. Leaf surface area was calculated using the magic wand tool in Adobe Photoshop CC 2018.

\section{Gas Chromatography - Mass Spectrometry (GC-MS) Settings} GC-MS analyses were performed on an Agilent 7890A GC (Agilent Technologies, Santa Clara, CA, USA) equipped with a HP-5MS column (30 m x $0.25 \mathrm{~mm} \times$ $0.25 \mu \mathrm{m})$ and an autosampler $(7693 \mathrm{~A})$, injector temperature $250^{\circ}$, interface temperature $250{ }^{\circ} \mathrm{C}$. The GC was connected to a JEOL AccuTOF-GCv JMS-100 mass spectrometer (JEOL Ltd., Akishima, Tokyo, Japan). For the analysis, $2 \mu \mathrm{l}$ of each sample was injected onto the GC column using a split ratio of 10:1 and the following temperature program: $50{ }^{\circ} \mathrm{C}$ for $2 \mathrm{~min}$., ramp $40{ }^{\circ} \mathrm{C} / \mathrm{min}$. to $200{ }^{\circ} \mathrm{C}$, hold $1 \mathrm{~min}$., ramp $3{ }^{\circ} \mathrm{C} / \mathrm{min}$. to $320{ }^{\circ} \mathrm{C}$, hold 13.25 min. using a helium (5.0 ) column flow of $1.0 \mathrm{ml} /$ min Electron Impact Spectra were acquired at $10 \mathrm{~Hz}$ (spectra per second) mass range 35-650.
Data Processing GC-MS peaks were manually integrated using MassCenter (JEOL Ltd., Akishima, Tokyo, Japan). Peaks after 16 minutes were selected, which included all wax metabolites and not the cutin metabolites (FernandezMoreno et al. 2016). Peaks were identified based on MS spectra (NIST library) and reference standards $\left(\mathrm{C}_{21}-\mathrm{C}_{40} n\right.$-alkanes, 1-octacosanol, $\alpha$-amyrin (Sigma-Aldrich), $\beta$-sitosterol, stigmasterol (LGC)). Iso-alkanes were identified by their $[\mathrm{M}-43]^{+}$peak (Fernandez-Moreno et al. 2016). Five unidentified peaks were present in all samples in similar proportions and accounted for $<5 \%$ of the total wax content (data not shown). Each peak area was corrected for total leaf area and the internal standard to obtain the concentration of metabolites in $\mu \mathrm{g} / \mathrm{dm}^{2}$ leaf area.

\section{Statistical Analyses}

Statistical analyses were performed in $\mathrm{R}$ version 3.5.1 ( $\mathrm{R}$ core team 2008). Differences in damage among the accessions in the thrips leaf disc choice assay were tested with a FriedmanANOVA for dependent samples. The differences between accessions in the no-choice assays (whole plant and leaf disc) were analyzed with ANOVA, except for the damage classes in the whole plant assay which were analyzed with a nonparametric Kruskal-Wallis test. Accessions were set as fixed factors in these models. Leaf wax metabolites were first analyzed with Principal Component Analyses (PCA) for overall differences among the two Capsicum species. Difference in concentrations of individual metabolites between resistant and susceptible accessions within each species (C. annuum or C. chinense) were analyzed with non-parametric MannWhitney U-tests. $P$-values were corrected for multiple comparisons with FDR correction, and significance levels set at $P<0.014$. Differences in total wax content between resistant and susceptible accessions were tested with ANOVA with resistance as fixed factor, total wax content data were log transformed to meet the assumption of normal distribution and homoscedasticity.

\section{Results}

\section{Thrips Resistance Assessment}

The classification of relative thrips resistance or susceptibility of the accessions was based on the leaf disc choice assays (Table 1, Macel et al. 2019). This resistance classification was compared with resistance in whole plant thrips performance assays and in no-choice leaf discs feeding damage assays (Visschers et al. 2019a) (Table 1). All three thrips tests showed that accession 43 is consistently susceptible, whereas accession 63 and 23 were the most resistant $C$. annuum accessions in all assays (Table 1). Thrips resistance of the other 
accessions was variable among the different assays. Accession 52 received the most damage in the leaf disc choice assay and was also one of the most susceptible accessions in the whole plant assay. Accession 19 was relatively resistant in the leaf disc assays, but less so in the whole plant test where it harbored a high number of thrips adults and larvae. Accession 34 showed a reverse pattern, being relatively susceptible in the leaf disc choice assay, but more resistant in the no-choice whole plant test. The $C$. chinense accessions were all relatively resistant in the no-choice whole plant assay, but in the nochoice leaf disc assay accession 13 and 70 were more susceptible (Table 1).

\section{Leaf Wax Metabolites}

The GC-MS cuticular wax analyses of leaves of the 11 accessions of the two Capsicum species yielded 35 metabolites (Table 2). These metabolites belonged to the classes of $n$ alkanes, branched iso-alkanes, long chain alcohols, and triterpenoids. We also detected a tropane alkaloid, identified by a NIST library match of 965 and accurate mass as tropacocaine, in most of the C. annuum accessions (Table 2, Table S2, Figure S1). The PCA plot of all data showed that leaves of $C$. annuum and $C$. chinense differed in wax metabolite composition (Fig. 1). Most metabolites were present in all samples, but 1-octacosanol $\left(\mathrm{C}_{28}\right.$ alcohol $)$ was the most abundant wax metabolite of $C$. annuum, while 1-triacotanol $\left(\mathrm{C}_{30}\right.$ alcohol) was the most abundant wax metabolite of C. chinense (Table 2).

Wax metabolites varied among the different accessions (Table S2). Within C. annuum, thrips susceptible accessions had on average significantly higher levels of $\mathrm{C}_{25}-\mathrm{C}_{29} n$-alkanes as well as of some iso-alkanes and an unknown alkyl ester, compared to resistance accessions (Table 2). For
C. chinense, the susceptible accessions had significantly higher levels of $\mathrm{C}_{37} n$-alkane. Resistant $C$. chinense had higher levels of the phytosterol $\beta$-amyrin (Table 2). Our analyses did not reveal any metabolites that had significantly higher concentrations in thrips resistant accessions of C. annuum, although there is a trend for higher levels of $\alpha$ amyrin in the wax layer of resistant accessions $(P=0.047$, Table 2). Total wax content tended to be higher in susceptible accessions of $C$. annuum compared to resistant accessions $(P=0.04$, Table 2).

\section{Discussion}

Our analyses of the cuticular wax metabolites of the leaves of Capsicum accessions showed that accessions that were relatively susceptible to western flower thrips had higher concentrations of cuticular $n$-alkanes and branched iso-alkanes than accessions that were more resistant. Triterpenoid amyrins tended to be higher in more resistant pepper accessions. The thrips assays could consistently identify the most and least resistant Capsicum accessions, even though the assays varied a little with regards to the exact ranking of the accessions.

Our study suggests that susceptibility to western flower thrips in pepper plants correlates with high concentrations of wax alkanes. Onion thrips (Thrips tabaci) also preferred onion accessions with high concentrations of epicuticular $n$-alkanes and total wax content (Damon et al. 2014). Partly, the effect of wax chemical composition depends on the insect and the plant species (Eigenbrode and Espelie 1995). Some insects can use the plant wax metabolites, and specifically the alkanes, as oviposition stimulants (e.g. Spencer 1996, Müller and Hilker 2001, Mitra et al. 2017). The reasons why thrips or other insects prefer

Table 1 Thrips (Frankliniella occidentalis) preference (damage \% in choice assay) and performance (numbers of larvae and adults) on Capsicum annuum and Capsicum chinense accessions in different tests

(data of the leaf disc choice test from Macel et al. 2019, data of the leaf disc no-choice test from Visschers et al. 2019a)

\begin{tabular}{|c|c|c|c|c|c|c|c|c|c|c|c|c|c|c|}
\hline \multirow[b]{2}{*}{ Scale } & \multirow[b]{2}{*}{ Test } & \multirow[b]{2}{*}{ Trait } & \multicolumn{7}{|c|}{ Means C. annuum accessions } & \multicolumn{4}{|c|}{ Means C. chinense accessions } & \multirow[b]{2}{*}{$P$-value } \\
\hline & & & $14-\mathrm{S}$ & $34-S$ & $43-\mathrm{S}$ & $52-\mathrm{S}$ & $19-\mathrm{R}$ & $23-\mathrm{R}$ & $63-\mathrm{R}$ & $38-\mathrm{S}$ & $13-\mathrm{R}$ & $41-\mathrm{R}$ & $70-\mathrm{R}$ & \\
\hline \multirow[t]{2}{*}{ Leaf disc } & Choice & $\begin{array}{l}\text { Damage } \\
(\%)\end{array}$ & 13.9 & 13.9 & 18.3 & 20.6 & 4.6 & 5.8 & 1.9 & 9.8 & 4.5 & 2.8 & 4.1 & $<0.001$ \\
\hline & No-choice & Damage $\left(\mathrm{mm}^{2}\right)$ & 9.4 & 6.5 & 19.7 & 3.1 & 2.8 & 1.2 & 1 & 7.3 & 23.2 & 5.0 & 26.1 & $<0.001$ \\
\hline \multirow[t]{3}{*}{ Whole plant } & No-choice & $\begin{array}{l}\text { Damage } \\
\text { (level 1-9) }\end{array}$ & 5.5 & 5.7 & 2.2 & 3.0 & 4.2 & 5.6 & 5.7 & 7.8 & 7.5 & 8.0 & 8.2 & $<0.001$ \\
\hline & & Larvae & 73 & 75 & 441 & 204 & 283 & 30 & 74 & 7 & 23 & 16 & 5 & $<0.001$ \\
\hline & & Adults & 92 & 30 & 122 & 172 & 44 & 40 & 47 & 9 & 19 & 7 & 7 & $<0.001$ \\
\hline
\end{tabular}

RU accessions numbers are given, $\mathrm{R}$ indicates an accession classified as resistant, $\mathrm{S}$ susceptible as determined in Macel et al. 2019. Damage levels at the whole plant tests range from 1 (severe damage) to 9 (no damage). $P$-values of Friedman-ANOVA (leaf disc choice test) and ANOVA (no-choice tests: damage $\mathrm{mm}^{2}$, larvae and adults) or Kruskal-Wallis (no-choice test: damage level) for differences among accessions 
Fig. 1 Principal component analysis plot of the relative abundance of 35 epicuticular leaf wax metabolites of Capsicum annuum (red dots) and Capsicum chinense (blue dots). The dots represent individual plant samples

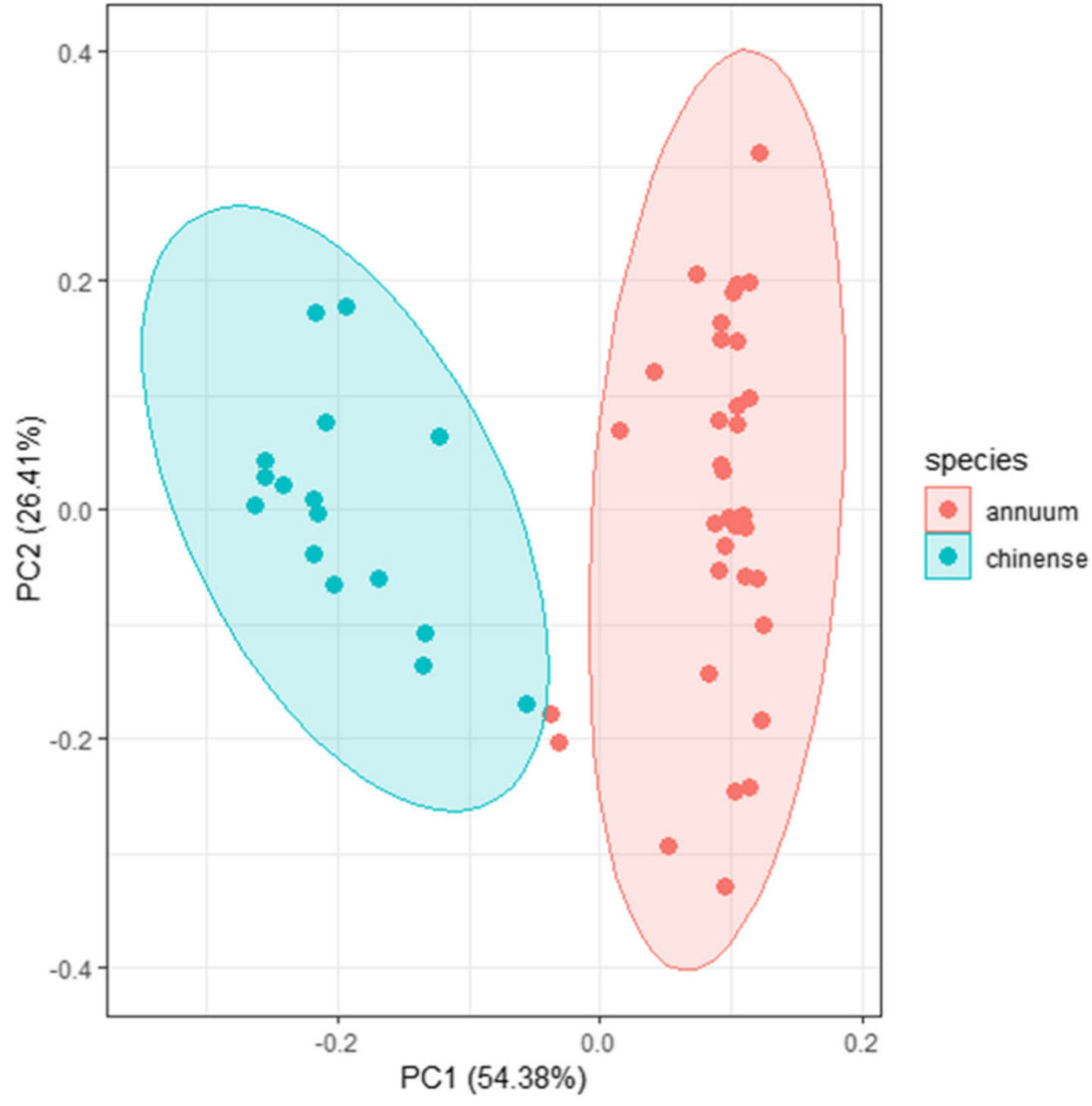

plants with more alkanes are thus far unknown. Possibly, the alkanes of the plant cuticular wax layer act as feeding stimulant to thrips. The epicuticula of insects consists of compounds very similar to the plant waxes, and insects may acquire these cuticular hydrocarbons through their food (Silverman and Liang 2000). Strikingly, the epicuticula of $F$. occidentalis consists of $\mathrm{C}_{25}-\mathrm{C}_{29} n$-alkanes (Gołebiowski et al. 2007), and exactly these same $n$ alkanes were more abundant in cuticular waxes of thrips susceptible Capsicum accessions. Whether thrips, like ants, acquire alkanes through their food is still unknown (Silverman and Liang 2000). It is also possible that other defensive traits that are correlated with wax alkanes determine thrips feeding damage. A third possibility could be that low amounts of alkanes increases the permeability of the cuticle, and more easily exposes plant defense metabolites to the leaf surface (Bessire et al. 2007).

C. annuum and C. chinense accessions had distinct leaf wax compositions. Wax metabolite profiles are known to be plant species specific (Mariani and Wolters-Arts 2000), which may be why insects have evolved to use wax components as reliable oviposition cue to select their host plant species. Wax composition also varies with plant age and plant organ (Lee and Suh 2015) and can change upon herbivory (Zhao et al. 2020). In our study of waxes of pepper leaves, $\mathrm{C}_{27}, \mathrm{C}_{31}$ and $\mathrm{C}_{33} n$-alkanes were the most abundant alkanes. The major alkanes in pepper fruit wax were $\mathrm{C}_{29}$ and $\mathrm{C}_{31} n$-alkanes (Bauer et al. 2005; de Rijke et al. 2015; Parson et al. 2013), which shows that the wax composition may differ among organs. Genes involved in biosynthesis of cuticular waxes have been identified in Arabidopsis and other models species such as Hordeum (Lee and Suh 2015). The pepper genome has been sequenced (Kim et al. 2014), but the effort to unravel the genes involved in cuticular wax biosynthesis in pepper is not as advanced as in Arabidopsis or tomato. So far, mainly candidate genes involved in cuticle development have been identified (Popovsky-Sarid et al. 2017). Next to genetic factors, abiotic conditions such as drought stress can also influence cuticular wax composition (Shepherd and Griffiths 2006). In addition, microbes and insects, for example feeding by the Hessian fly, can alter plant leaf wax profiles (Aragón et al. 2017; Kosma et al. 2010; Silva et al. 2014). Leaf cuticular wax composition is thus both genetically and environmentally determined. Furthermore, microbes that live in or on the plant surface can also produce specific metabolites (Schmidt et al. 2018). Endophytic fungi are known to produce tropane alkaloids (Naik et al. 2018). It is possible that the tropane alkaloid we detected in low amounts in the pepper leaf wax is of microbial origin, rather than produced by the plant itself. Although the compound could only be detected in some $C$. annuum accessions, the 


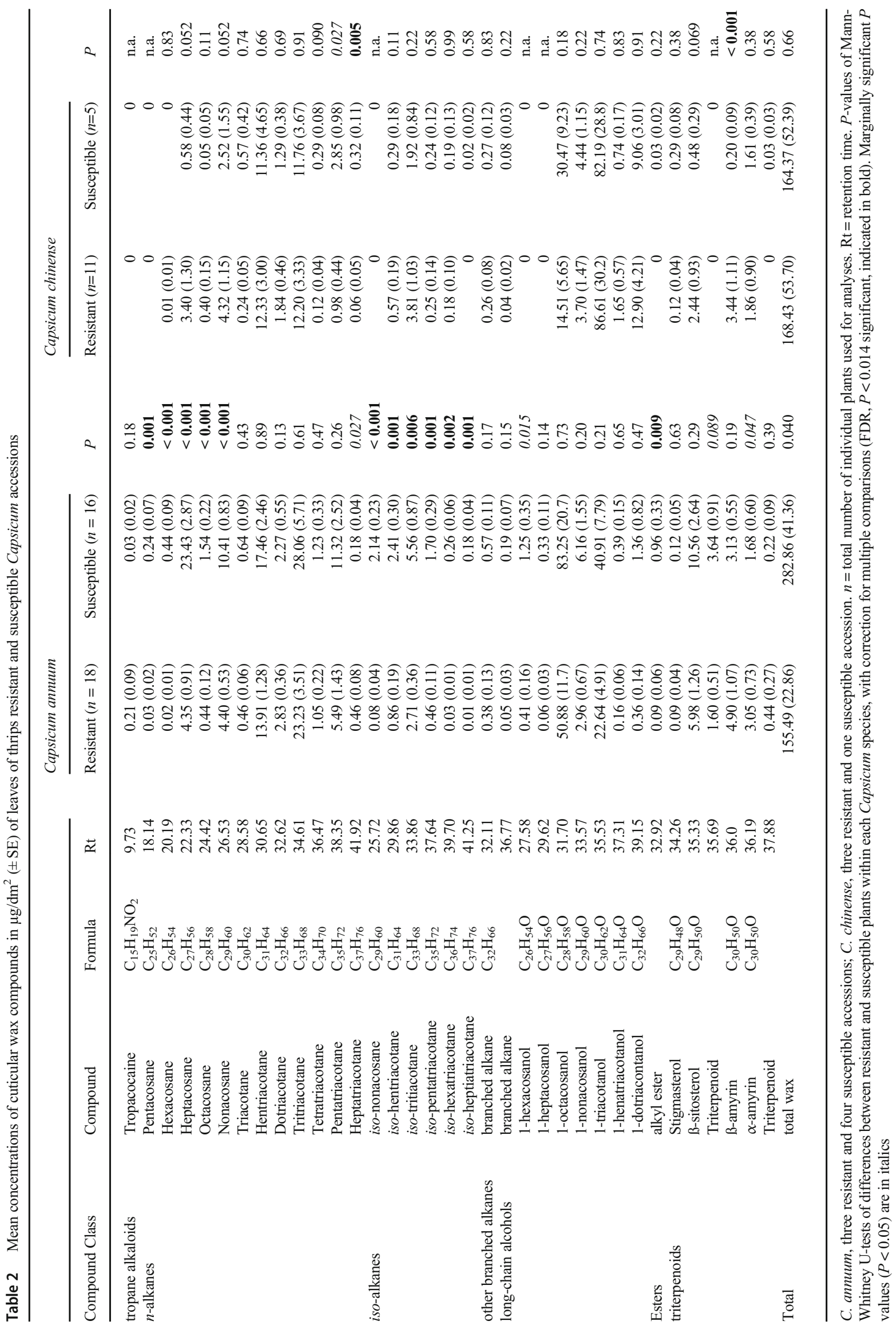


tropane alkaloid does not seem to be related to thrips resistance (Table S2). Further studies are needed to determine the origin and the function of this alkaloid in Capsicum.

Some triterpenoids, the amyrins, were higher in resistant pepper accessions. Maharijaya et al. (2012) also found high concentrations of an unknown triterpenoid (phytosterol) in resistant pepper accessions. Triterpenoids are known to have a deterrent effect on feeding and oviposition of some insects, such as Plutella xylostella and Phyllotreta nemorum (Eigenbrode and Pillai 1998; Kuzina et al. 2009). Amyrins are the backbone structures for insect-deterrent saponins (Khakimov et al. 2015). In our study, the variation in $\alpha$-amyrin levels among the different C. annuиm accessions was considerable and therefore only weakly significant different between resistant and susceptible plants. $\beta$-Amyrin concentrations were low in the susceptible $C$. chinense accession compared to the resistant $C$. chinense accessions. However, within the $C$. chinense group our statistical power was low. Our analysis indicates that amyrins and structurally related compounds may serve as leads for thrips resistance breeding.

We tested thrips damage on the Capsicum accessions in three different thrips assays. Damage levels of the accessions varied among the three tests, but the least and most resistant accessions remained constant throughout all three trials (Visschers et al. 2019a, Macel et al. 2019). Plant resistance to insects is at least partly determined by plant age and by the environment, as is shown in many other studies (e.g. Damon et al. 2014; Visschers et al. 2019a 2019b). Nevertheless, Capsicum accessions that had consistent relatively low feeding damage and thrips numbers, had low concentrations of the cuticular wax $\mathrm{C}_{25}-\mathrm{C}_{29}$ alkanes. Further validation with, for example, wax mutant lines could elucidate the role of these alkanes in thrips resistance or susceptibility. This could also reveal whether wax layer composition is more important for insect resistance than the total amount of wax (Aragon et al. 2017). The cuticular wax layer also plays an important role in resistance to pathogens and protection against desiccation and UV light. Breeding for thrips resistance in peppers by manipulating the leaf and fruit wax layer composition and quantity therefore will have to balance the different costs and benefits of these wax metabolites.

Acknowledgements We thank Julia Mars, Lynn Vorstenbosch, and Peter van Galen for their help with the GC-MS analyses, Jan Bruin for his help with the thrips whole plant assay, and the Radboud greenhouse staff for their assistance in the greenhouses. Nicole M. van Dam gratefully acknowledges the support of the German Centre for Integrative Biodiversity Research (iDiv) Halle-Jena-Leipzig funded by the German Research Foundation (FZT 118). This research was funded by the NWO Domain Applied and Engineering Sciences (AES) and is part of the Perspectief program Green defense Against Pest (GAP), project 13552.
Open Access This article is licensed under a Creative Commons Attribution 4.0 International License, which permits use, sharing, adaptation, distribution and reproduction in any medium or format, as long as you give appropriate credit to the original author(s) and the source, provide a link to the Creative Commons licence, and indicate if changes were made. The images or other third party material in this article are included in the article's Creative Commons licence, unless indicated otherwise in a credit line to the material. If material is not included in the article's Creative Commons licence and your intended use is not permitted by statutory regulation or exceeds the permitted use, you will need to obtain permission directly from the copyright holder. To view a copy of this licence, visit http://creativecommons.org/licenses/by/4.0/.

\section{References}

Aragón W, Reina-Pinto JJ, Serrano M (2017) The intimate talk between plants and microorganisms at the leaf surface. J Exp Bot 68:5339-5350

Bauer S, Schulte E, Thier HP (2005) Composition of the surface waxes from bell pepper and eggplant. Eur Food Res Technol 220:5-10

Bessire M, Chassot C, Jacquat AC, Humphry M, Borel S, Petétot JMDC, Métraux JP, Nawrath C (2007) A permeable cuticle in Arabidopsis leads to a strong resistance to Botrytis cinerea. EMBO J 26:2158-2168

Braccini CL, Vega AS, Coll Aráoz MV, Teal PE, Cerrillo T, Zavala JA, Fernandez PC (2015) Both volatiles and cuticular plant compounds determine oviposition of the willow sawfly Nematus oligospilus on leaves of Salix spp. (Salicaceae). J Chem Ecol 41:985-996

Busta L, Hegebarth D, Kroc E, Jetter R (2017) Changes in cuticular wax coverage and composition on developing Arabidopsis leaves are influenced by wax biosynthesis gene expression levels and trichome density. Planta 245:297-311

Damon SJ, Groves RL, Havey MJ (2014) Variation for epicuticular waxes on onion foliage and impacts on numbers of onion thrips. $\mathrm{J}$ Am Soc Hortic Sci 139:495-501

de Rijke E, Fellner C, Westerveld J, Lopatka M, Cerli C, Kalbitz K, de Koster CG (2015) Determination of n-alkanes in C. annuum (bell pepper) fruit and seed using GC-MS: comparison of extraction methods and application to samples of different geographical origin. Anal Bioana Cchem 407:5729-5738

Eigenbrode SD, Espelie KE (1995) Effects of plant epicuticular lipids on insect herbivores. Annu Rev Ecol Evol Syst 40:171-194

Eigenbrode SD, Pillai SK (1998) Neonate Plutella xylostella responses to surface wax components of a resistant cabbage (Brassica oleracea). J Chem Ecol 24:1611-1627

Fernandez-Moreno JP, Malitsky S, Lashbrooke J, Biswal AK, Racovita RC, Mellerowicz EJ, Jetter R, Orzaez D, Aharoni A, Granell A (2016) An efficient method for medium throughput screening of cuticular wax composition in different plant species. Metabolomics 12:1-13

Gołebiowski M, Maliński E, Nawrot J, Szafranek J, Stepnowski P (2007) Identification of the cuticular lipid composition of the western flower thrips Frankliniella occidentalis. Comp Biochem Physio B Biochem Mol Biol 147:288-292

Haslam TM, Kunst L (2013) Wax analysis of stem and rosette leaves in Arabidopsis thaliana. Bio-protocol 3(11):e782. https://doi.org/10. 21769/BioProtoc. 782

Jenks MA, Tuttle HA, Eigenbrode SD, Feldmann KA (1995) Leaf epicuticular waxes of the Eceriferum mutants in Arabidopsis. Plant Physiol 108:369-377 
Khakimov B, Kuzina V, Erthmann P, Fukushima EO, Augustin JM, Olsen CE, Scholtalbers J, Volpin H, Andersen SB, Hauser TP et al (2015) Identification and genome organization of saponin pathway genes from a wild crucifer, and their use for transient production of saponins in Nicotiana benthamiana. Plant J 84:478-490

Kim S, Park M, Yeom SI, Kim YM, Lee JM, Lee HA, Seo E, Choi J, Cheong K, Kim KT et al (2014) Genome sequence of the hot pepper provides insights into the evolution of pungency in Capsicum species. Nat Genet 46:270-278

Kosma DK, Nemacheck JA, Jenks MA, Williams CE (2010) Changes in properties of wheat leaf cuticle during interactions with Hessian fly. Plant J 63:31-43

Kuzina V, Ekstrom CT, Andersen SB, Nielsen JK, Olsen CE, Bak S (2009) Indentification of defense compounds in Barbarea vulgaris against Phyllotreta nemorum by an ecometabolomics approach. Plant Physiol 151:1977-1990

Lee SB, Suh MC (2015) Advances in the understanding of cuticular waxes in Arabidopsis thaliana and crop species. Plant Cell Rep 34:557-572

Leiss KA, Maltese F, Choi YH, Verpoorte R, Klinkhamer PGL (2009) Identification of chlorogenic acid as a resistance factor for thrips in chrysanthemum. Plant Physiol 150:1567-1575

Liu X, Vrieling K, Klinkhamer PGL (2019) Phytochemical background mediates effects of pyrrolizidine alkaloids on western flower thrips. J Chem Ecol 45:116-127. https://doi.org/10. 1007/s10886-018-1009-2

Macel M, Visschers IGS, Peters JL, Kappers IF, de Vos RCH, van Dam NM. 2019. Metabolomics of thrips resistance in pepper (Capsicum spp.) reveals monomer and dimer acyclic diterpene glycosides as potential chemical defenses. J Chem Ecol 45:490-501

Maharijaya A, Vosman B, Verstappen F, Steenhuis-Broers G, Mumm R, Purwito A, Visser RGF, Voorrips RE (2012) Resistance factors in pepper inhibit larval development of thrips (Frankliniella occidentalis). Entomol Exp Appl 145:62-71

Maharijaya A, Vosman B, Pelgrom K, Wahyuni Y, de Vos RCH, Voorrips RE (2018) Genetic variation in phytochemicals in leaves of pepper (Capsicum) in relation to thrips resistance. Arthropod-Plant Interactions 13:1-9. https://doi.org/10.1007/ s11829-018-9628-7

Mariani C, Wolters-Arts M (2000) Complex Waxes. Plant Cell 12: 1795-1798

Mitra S, Sarkar N, Barik A (2017) Long-chain alkanes and fatty acids from Ludwigia octovalvis weed leaf surface waxes as short-range attractant and ovipositional stimulant to Altica cyanea (Weber) (Coleoptera: Chrysomelidae). Bull Entomol Res 107:391-400

Müller C, Hilker M (2001) Host finding and oviposition behavior in a chrysomelid specialist - The importance of host plant surface waxes. J Chem Ecol 27:985-994

Naik T, Vanitha SC, Rajvanshi PK, Chandrika M, Kamalraj S, Jayabaskaran C. 2018. Novel microbial sources of tropane alkaloids: first report of production by endophytic fungi isolated from Datura metel L. Curr Microbiol 75: 206-212

Parsons EP, Popopvsky S, Lohrey GT, Alkalai-Tuvia S, Perzelan Y, Bosland P, Bebeli PJ, Paran I, Fallik E, Jenks MA. 2013. Fruit cuticle lipid composition and water loss in a diverse collection of pepper (Capsicum). Physiol Plant 149: 160-174

Popovsky-Sarid S, Borovsky Y, Faigenboim A, Parsons EP, Lohrey GT, Alkalai-Tuvia S, Fallik E, Jenks MA, Paran I (2017) Genetic and biochemical analysis reveals linked QTLs determining natural variation for fruit post-harvest water loss in pepper (Capsicum). Theor Appl Genet 130:445-459

R Core Team (2008) R: A language and environment for statistical computing. R Foundation for Statistical Computing, Vienna, Austria. https://www.R-project.org/

Schmidt R, Durling MB, de Jager V, Menezes RC, Nordkvist E, Svatoš A, Dubey M, Lauterbach L, Dickschat JS, Karlsson M et al (2018) Deciphering the genome and secondary metabolome of the plant pathogen Fusarium culmorum. FEMS Microbiol Ecol 94(6):508515

Shepherd T, Griffiths DW (2006) The effects of stress on plant cuticular waxes. New Phytol 171:469-499

Shipp JL, Wang K, Binns MR (1998) Economic injury levels for western flower thrips (Thysanoptera: Thripidae) on greenhouse cucumber. J Econ Entomol 93:1732-1740

Silva LR, Azevedo J, Pereira MJ, Carro L, Velazquez E, Peix A, Andrade PB (2014) Inoculation of the nonlegume Capsicum annuum (L.) with Rhizobium. J Agric Food Chem 62:565-573

Silverman D, Liang J (2000) 'You are what you eat': Diet modifies cuticular hydrocarbons. Naturwissenschaften 87:412-416

Spencer JL (1996) Waxes enhance Plutella xylostella oviposition in response to sinigrin and cabbage homogenates. Entomol Exp Appl 81: $165-173$

Steenbergen M, Abd-El-Haliem A, Bleeker P, Dicke M, Escobar-Bravo R, Cheng G, Haring MA, Kant MR, Kappers I, Klinkhamer PGL et al (2018) Thrips advisor: Exploiting thrips-induced defences to combat pests on crops. J Exp Bot 69:1837-1848

Udayagiri S, Mason CE (1997) Epicuticular wax chemicals in zea mays influence oviposition in Ostrinia nubilalis. J Chem Ecol 23:1675-1687

Visschers IGS (2020) Self-defense in Pepper - Identifying natural resistance to thrips in Capsicum. $\mathrm{PhD}$ thesis, Radboud University, Nijmegen, the Netherlands. ISBN: 978-94-6402-022-9

Visschers IGS, Dam NM, Van Peters JL (2018a) An objective highthroughput screening method for thrips damage quantitation using Ilastik and ImageJ. Entomol Exp Appl 166(6):fiy078

Visschers IGS, van Dam NM, Peters JL (2018b) Quantification of thrips damage using Ilastik and ImageJ Fiji, Bio-protocol 8(8):e2806. https://doi.org/10.21769/BioProtoc.2806

Visschers IGS, Peters JL, van de Vondervoort JAH, Hoogveld RHM, van Dam NM (2019) Thrips resistance screening is coming of age: Leaf position and ontogeny are important determinants of leaf-based resistance in pepper. Front Plant Sci. https://doi.org/10.3389/fpls. 2019.00510

Visschers IGS, Peters JL, Timmermans LH, Edwards E, Ferrater JB, Balatero CH, Stratongjun M, Bleeker PM, van Herwijnen Z, Glawe GA, Bruin J, van Dam NM, Macel M (2019) Resistance to three thrips species in Capsicum spp. depends on site conditions and geographic regions. J Appl Entomol 143:929-941

Vrieling K, Derridj S (2003) Pyrrolizidine alkaloids in and on the leaf surface of Senecio jacobaea L. Phytochemistry 64:1223-1228

Zhang J, Li Y, Guo J, Du B, He G, Zhang Y, Chen R, Li J (2018) Lipid profiles reveal different responses to brown planthopper infestation for pest susceptible and resistant rice plants. Metabolomics 14: 120 . https://doi.org/10.1007/s11306-018-1422-0

Zhao X, Chen S, Wang S, Shan W, Wang X, Lin Y, Su F, Yang Z, Yu X (2020) Defensive responses of tea plants (Camellia sinensis) against tea green leafhopper attack: a multi-omics study. Front. Plant Sci. 10:1705. https://doi.org/10.3389/fpls.2019.01705 